\title{
A FIXED POINT THEOREM FOR CARISTI-TYPE CYCLIC MAPPINGS
}

\author{
NARONGSUK BOONSRI* AND SATIT SAEJUNG**1 \\ *Department of Mathematics, Faculty of Science, Khon Kaen University \\ Khon Kaen, 40002, Thailand \\ E-mail: narongsukboonsri@gmail.com \\ ** Department of Mathematics, Faculty of Science, Khon Kaen University \\ Khon Kaen, 40002, Thailand \\ and Research Center for Environmental and Hazardous Substance Management \\ Khon Kaen University, Thailand \\ E-mail: saejung@kku.ac.th
}

\begin{abstract}
We discuss two results for Caristi-type cyclic mappings due to Du and Karapinar [3]. We show that they can be deduced from our best proximity point theorem. Our result can be regarded as a generalized result of a fixed point theorem proved by Bollenbacher and Hicks [1] in the setting of cyclic mappings.

Key Words and Phrases: Best proximity point, fixed point, Caristi-type cyclic mapping, orbitally lower semicontinuity.

2010 Mathematics Subject Classification: 47H09, 47H10, 54E50.
\end{abstract}

Acknowledgements. The first author is thankful to the Development and Promotion of Science and Technology Talents Project (DPST) for financial support. The second author was partially supported by the Research Center for Environmental and Hazardous Substance Management, Khon Kaen University.

\section{REFERENCES}

[1] A. Bollenbacher, T.L. Hicks, A fixed point theorem revisited, Proc. Amer. Math. Soc., 102(1988), 898-900.

[2] J. Caristi, Fixed point theorems for mappings satisfying inwardness conditions, Trans, Amer. Math. Soc., 215(1976), 241-251.

[3] W.-S. Du, E. Karapinar, A note on Caristi-type cyclic maps: related results and applications, Fixed Point Theory Appl., 2013, 2013:344, 13 pp.

[4] J. Eisenfeld, V. Lakshmikantham, Fixed point theorems on closed sets through abstract cones, Appl. Math. Comput., 3(1977), no. 2, 155-167.

[5] T.L. Hicks, B.E. Rhoades, A Banach type fixed-point theorem, Math. Japon., 24(1979/80), no. $3,327-330$.

\footnotetext{
${ }^{1}$ Corresponding author.
} 
[6] O. Kada, T. Suzuki, W. Takahashi, Nonconvex minimization theorems and fixed point theorems in complete metric spaces, Math. Japon., 44(1996), no. 2, 381-391.

[7] N. Mizoguchi, W. Takahashi, Fixed point theorems for multivalued mappings on complete metric spaces, J. Math. Anal. Appl., 141(1989), no. 1, 177-188.

Received: May 20, 2015; Accepted: January 23, 2016. 